\title{
Parametric studies on the ductility of axial loaded square reinforced concrete column made of normal-strength concrete (NSC) and high-strength steel confining rebar (HSSCR) with various ties configuration
}

\author{
Anis Aulia Ulfa ${ }^{1}$, Bambang Piscesa ${ }^{1 *}$, Mario M. Attard ${ }^{2}$, Faimun Faimun $^{1}$, Pujo Aji ${ }^{1}$ \\ ${ }^{1}$ Civil Engineering Department, Institut Teknologi Sepuluh Nopember, 60111 Surabaya, Indonesia \\ ${ }^{2}$ School of Civil and Environmental Engineering, University of New South Wales, NSW 2052, Sydney, Australia
}

\begin{abstract}
During an earthquake, Reinforced Concrete (RC) building structures should behave in a ductile manner to prevent the structures from collapse. Therefore, the column element should have sufficient ductility to sustain an axial load at the post-peak region. Ductility of the RC column can be sufficiently provided by confinement to the RC column core. Therefore, in this paper, ductility of square RC columns made of NSC and HSSCR are analyzed using three-dimensional nonlinear finite element analysis (3D-NLFEA) with various ties configurations. In total, 12 specimens for each transverse steel rebar configuration were examined. The measurement used for ductility comparisons is the $\mathrm{I}_{10}$ index (AS 3600-2018) which is compared with the concept of ductility available in the literature (for example ACI 318-14). The study found that the computed minimum transverse steel rebar diameter based on ACI 318-14 showed larger diameter than the AS 3600:2018. From the 3DNLFEA analysis found that using a confining rebar higher than $700 \mathrm{MPa}$ with the same volumetric ratio shows lower ductility for the Type I RC column configuration.
\end{abstract}

\section{Introduction}

A special resisting moment frames structure should be designed based on the Strong Column Weak Beam (SCWB) concept plus specific detailing for each element. Plastic hinges should be designed properly to occur mainly on the beam element and at the base of the column. The purpose of this is to avoid structural collapse and give people inside a building enough time to save themselves during an earthquake event. To achieve this, reinforced concrete columns should be designed properly such that column strength and ductility meet the minimum requirements as stated in the building codes. For RC columns, both strength and ductility can be enhanced by using transverse steel such as hoops and/or ties [1].

Rebar configuration also plays an important role in the confinement stress distribution. If the lateral force produced by the ties or hoops is well distributed around the concrete core, the confining pressure distribution will be more uniform and thus the effectiveness of the confinement increases [2]. On the other hand, the strength and ductility enhancement of the RC column are strongly affected by the confining rebar configuration and characteristics such as the volumetric ratio, the pitch spacing, the diameter, and the yield strength of the rebar [3]. The internal confinement of a concrete column depends on the configuration of lateral reinforcement [4]. A good confining rebar configuration can also prevent the longitudinal bar from buckling which can also increase the effective confining pressure [5].
The ductility of an RC column can be measured using the ductility index $\left(I_{10}\right)$ and as the concrete strength increases, the $I_{10}$ ductility index of the RC column decreases [5]. The use of high strength materials for confining reinforcing bars can result in larger pitch spacing and can increase the workability of the member during concrete casting. Hence, it is expected that the use of HSSCR in RC columns will further enhance the strength and ductility of the concrete core [6] and reduce the material usage to achieve a more economical structural system [8]. In AS 3600-2018, the maximum yield stress for the confining rebar is limited to $800 \mathrm{MPa}$, while in ACI 318-14, it is limited to $700 \mathrm{MPa}$. However, the effect of using this high-strength steel rebar still requires extensive research. It may not be appropriate to replace a normal-strength rebar with a high-strength rebar while maintaining the same volumetric ratio of the confining reinforcing bar.

In this paper, $12 \mathrm{RC}$ column were modeled and analyzed using 3D-NLFEA $[9,10]$. 3D-NLFEA utilizes the plasticity-fracture concrete constitutive model which is restraint sensitive $[11,12]$ and incorporates the premature cover spalling due to restrained shrinkage [13]. For each modeled RC column based on ACI 318-14 and AS 3600-2018, both the $I_{10}$ ductility index and the displacement ductility level were examined and compared. This investigation will show that using a confining rebar with a yield strength higher than $700 \mathrm{MPa}$ and maintaining the same volumetric ratio yields a lower

\footnotetext{
* Corresponding author: piscesa@ce.its.ac.id
} 
$I_{10}$ ductility index and lower displacement ductility level for a certain type of ties configuration.

\section{RC Column Model}

\subsection{Specimen Geometry Detail}

From the previous study [14], the effectiveness of the confinement of a square column is better than that of a rectangular column. In the current study, a total of 12 square RC column specimens with a cross-section size of $600 \times 600$ were investigated. All columns were set to a height of $1800 \mathrm{~mm}$. As shown in Fig. 1, there are two types of confining rebar configuration.

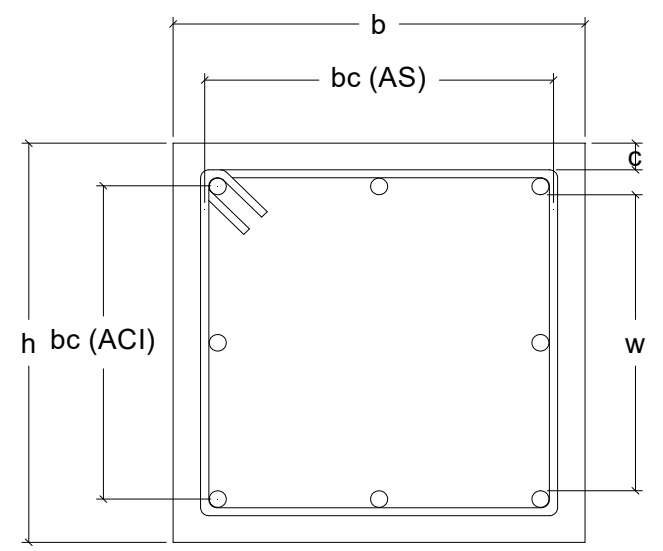

(a)

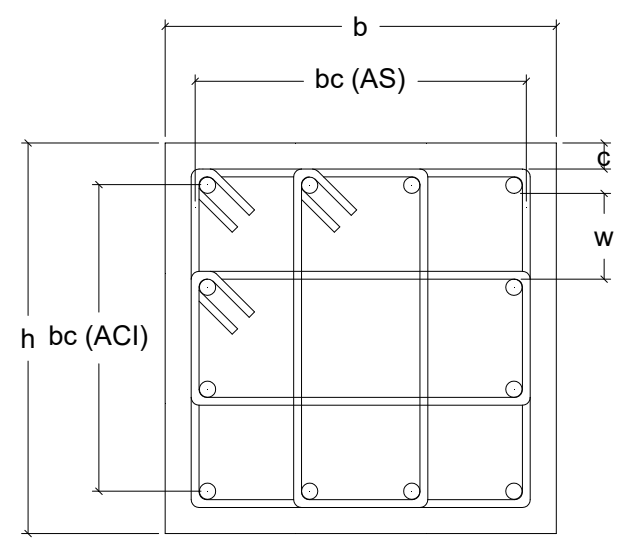

(b)

Fig. 1 Specimen confinement configurations (a) Type I and (b) Type II

The concrete cover (c) was $40 \mathrm{~mm}$. The diameter of the longitudinal bar was $25 \mathrm{~mm}$ for Type 1 and $20 \mathrm{~mm}$ for Type II corresponding to $1.09 \%$ (Type I) and $1.05 \%$ (Type II) longitudinal reinforcing ratios. The pitch confinement spacing was set to $100 \mathrm{~mm}$.

The concrete density, used to compute the modulus of elasticity of the concrete, was set to $2200 \mathrm{~kg} / \mathrm{m}^{3}$. Young's modulus for the reinforcing bar was set to $200 \mathrm{GPa}$. The concrete compressive strength was taken as $50 \mathrm{MPa}$. Two longitudinal rebar yield strengths were examined, 420 $\mathrm{MPa}$ and $500 \mathrm{MPa}$. For the transverse steel reinforcing bar, four levels of the rebar strength were used: $420 \mathrm{MPa}$, $500 \mathrm{MPa}, 700 \mathrm{MPa}$ and 1,000 MPa. Table 1 shows the label of the modeled RC column and its configurations.

Table 1. Labeling of the NSC and HSSCR Column Specimens

\begin{tabular}{|c|c|c|c|c|c|c|}
\hline$f_{\mathrm{c}}$ (MPa) & \multicolumn{5}{|c|}{50} \\
\hline$f_{\mathrm{y}}(\mathrm{MPa})$ & \multicolumn{3}{|c|}{420} & \multicolumn{3}{c|}{500} \\
\hline$f_{\mathrm{yt}}(\mathrm{MPa})$ & 420 & 700 & 1000 & 500 & 700 & 1,000 \\
\hline & $\begin{array}{c}\text { I5.L4. } \\
\text { T4* }\end{array}$ & $\begin{array}{c}\text { I5.L4. } \\
\text { T7 }\end{array}$ & $\begin{array}{c}\text { I5.L4. } \\
\text { T10* }\end{array}$ & $\begin{array}{c}\text { I5.L4. } \\
\text { T4* }\end{array}$ & $\begin{array}{c}\text { I5.L5.T } \\
7^{*}\end{array}$ & $\begin{array}{c}\text { I5.L5. } \\
\text { T10* }\end{array}$ \\
\hline & $\begin{array}{c}\text { II5. } \\
\text { L4.T4* }\end{array}$ & $\begin{array}{c}\text { II5.L4. } \\
\text { T7* }\end{array}$ & $\begin{array}{c}\text { II5. } \\
\text { L4.T10* }\end{array}$ & $\begin{array}{c}\text { II5. } \\
\text { L5.T4* }\end{array}$ & $\begin{array}{c}\text { II5. } \\
\text { L5.T7* }\end{array}$ & $\begin{array}{c}\text { L5.T10* } \\
\text { II5. }\end{array}$ \\
\hline & & & &
\end{tabular}

${ }^{*}$ Notes: I5 is Type I, $f_{c}^{\prime}=50 \mathrm{Mpa}$, II5 is Type II, $f_{c}^{\prime}=50 \mathrm{Mpa} ; \mathrm{L} 5$ is longitudinal steel reinforcement strength $f_{y}=500 \mathrm{Mpa}$, L4 for $420 \mathrm{Mpa}$; T4 is confining steel strength $f_{y t}=420 \mathrm{Mpa}$, T5 for $500 \mathrm{Mpa}, \mathrm{T} 7$ for 700 $\mathrm{Mpa}$, and $\mathrm{T} 10$ for $1000 \mathrm{MPa}$

\subsection{Modeling Technique, Constitutive Law, and Stress-Strain Behavior of The Reinforcing Bar}

The longitudinal rebar was modeled using embedded truss elements. It was assumed that perfect bonding could be achieved between the concrete and the rebar. The constitutive law of the rebar follows a one-dimensional plasticity model [9].

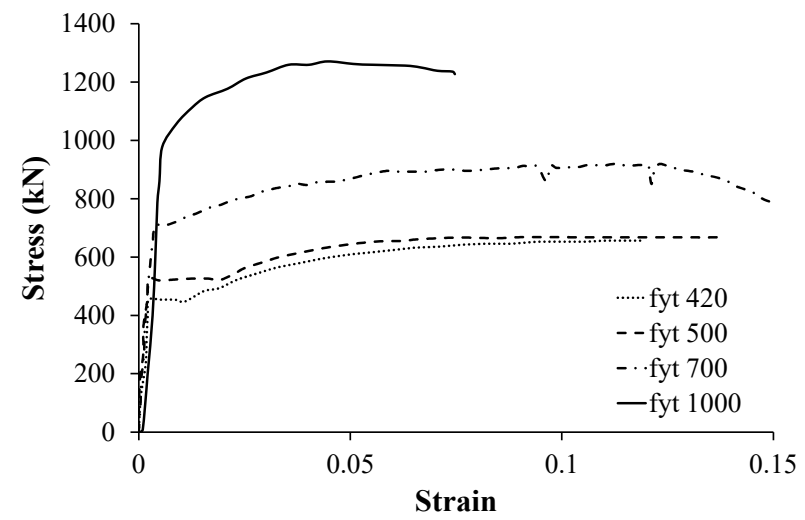

Fig. 2 The stress-strain diagram of the lateral confinement.

The elastic-perfectly plastic stress-strain law was used to model the behavior of the longitudinal bar. For the confining rebar, the stress-strain models were obtained from:

1. Saliem [15] for $420 \mathrm{MPa}$ steel rebar strength;

2. Nehrp [16] for $500 \mathrm{MPa}$ steel rebar strength;

3. Chung [17] for $700 \mathrm{MPa}$ steel rebar strength;

4. Chai [18] for $1000 \mathrm{MPa}$ steel rebar strength.

Fig. 2 shows the stress-strain diagram used for the confining rebar. 


\subsection{Minimum Confining Rebar Diameter}

The confining rebar diameter for ACI 318-14 was computed by keeping the volumetric ratio of the confining rebar the same, while for AS 3600-2018, the confining rebar diameter was computed by maintaining the same minimum confining pressure level. In AS 3600-2018, the confining pressure applied to the core of the column may be obtained by considering triaxial stresses across all sections and the effectiveness of fitments in providing the specified confinement.

The effective confining pressure $\left(f_{\text {reff }}\right)$ can be calculated using:

$$
f_{\text {r.eff }}=k_{\text {eff }} \cdot f_{\mathrm{r}} \geq 0.01 f_{\mathrm{c}}^{\prime}
$$

where $k_{\text {eff }}$ is the confinement effectiveness, $f_{\mathrm{r}}$ is the average confining pressure on the core cross-section taken at the level of ties or spirals. The expression for $k_{\text {eff }}$ is:

$$
k_{\mathrm{eff}}=\left(1-\frac{n w^{2}}{6 A_{\mathrm{c}}}\right)\left(1-\frac{s}{2 b_{\mathrm{c}}}\right)\left(1-\frac{s}{2 d_{\mathrm{c}}}\right)
$$

In the above equation, $n$ is the number of laterally restrained longitudinal bars, $w$ is the average clear spacing between adjacent tied longitudinal bars, $s$ is the center to center spacing of the ties along the column, $b_{\mathrm{c}}$ and $d_{\mathrm{c}}$ are the overall dimensions measured between the center-lines of the outmost confining bar and $A_{c}$ is the cross-sectional area of the core bounded by the center-line of the outermost confining bars (see AS 3600-2018 for more details).

For the non-circular section, AS 3600-2018 states that $f_{\mathrm{r}}$ is the smallest of the confining pressures calculated for each major direction as follows:

$$
f_{\mathrm{r}}=\frac{\sum_{i=1}^{m} A_{\mathrm{b} . \mathrm{fit}} f_{\mathrm{sy} . \mathrm{f}} \sin \theta}{d_{\mathrm{s}} s}
$$

$A_{\mathrm{b} \text {.fit }}$ is the area of one leg of the ties, $f_{\text {sy.f }}$ is the yield stress of the lateral bars, $m$ is the number of tie legs crossing the confinement plane, $\theta$ is the angle between the tie leg and the confining plane and $d_{\mathrm{s}}$ is the overall dimension measured between the center-lines of the outermost confining bars.

Using Eqn.(1), the uniform confining pressure can be calculated with:

$$
f_{\mathrm{r}}=\frac{0.01 f_{\mathrm{c}}^{\prime}}{k_{\mathrm{eff}}}
$$

By rearranging Eqns.(3) and (4), the area of one leg confining rebar can be obtained as:

$$
A_{\mathrm{b} . \mathrm{fit}}=\frac{f_{\mathrm{r}} d_{\mathrm{s}} s}{f_{\text {sy.f }} \sum_{i=1}^{m} \sin \theta}
$$

In ACI 318-2014 [19], for a concrete compressive strength lower than $70 \mathrm{MPa}$, the confining rebar ratio must be higher than:

$$
\begin{gathered}
\frac{A_{\mathrm{sh}}}{s . b_{c}}=0.3\left(\frac{A_{\mathrm{g}}}{A_{\mathrm{ch}}}-1\right) \frac{f_{\mathrm{c}}^{\prime}}{f_{\mathrm{sy} . \mathrm{f}}} \\
\frac{A_{\mathrm{sh}}}{s \cdot b_{c}}=0.09 \frac{f_{\mathrm{c}}^{\prime}}{f_{\mathrm{sy} . \mathrm{f}}} \\
A_{\mathrm{b} . \mathrm{fit}}=\frac{A_{\mathrm{sh}}}{m}
\end{gathered}
$$

Where $A_{s h}$ is the total cross-sectional area of the transverse reinforcement, $A_{g}$ is the gross area of the concrete section and $A_{c h}$ is the cross-sectional area of a member measured to the outer edge of the transverse reinforcement.

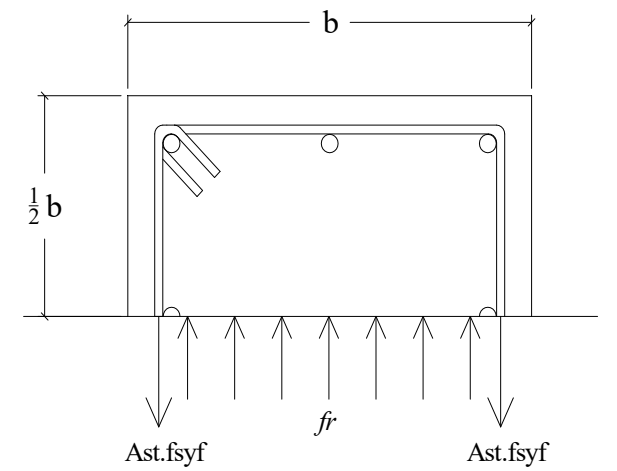

(a)

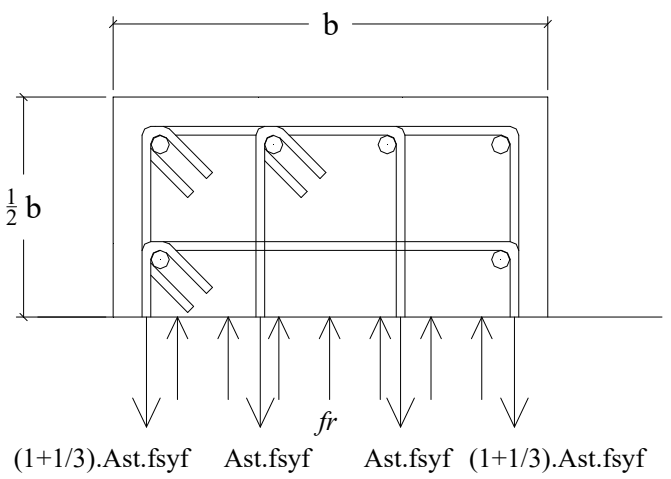

(b)

Fig. 3 Effect of Confining pressure for each tie configuration (a) Type I and (b) Type II

The required confining rebar was computed from the free body diagram of the rectangular section, as shown in Fig. 3.

The diameter for the confining rebar using ACI 31814 is shown in Table 2 while the one using AS 3600-2018 is shown in Table 3 . Tables 2 and 3 show that the minimum lateral bar diameter given by ACI 318-14 was larger than that yielded by AS 3600-2018. 
Table 2. Minimum lateral bar diameter of specimen according to ACI-318 2014

\begin{tabular}{ccccccc}
\hline No & $\begin{array}{c}\text { Column } \\
\text { Type }\end{array}$ & $\rho_{\mathbf{s 1}}$ & $\boldsymbol{\rho}_{\mathbf{s} 2}$ & $\mathbf{A}_{\text {sh }}$ & $\mathbf{n}_{\mathbf{s}}$ & $\mathbf{D}_{\mathbf{s}}$ \\
\hline 1 & I5.L4.T4 & 0.012 & 0.011 & 557.4 & 2 & 18.3 \\
\hline 2 & I5.L4.T7 & 0.007 & 0.006 & 334.44 & 2 & 14.1 \\
\hline 3 & I5.L4.T10 & 0.005 & 0.005 & 234.11 & 2 & 11.8 \\
\hline 4 & I5.L5.T5 & 0.010 & 0.009 & 468.21 & 2 & 16.7 \\
\hline 5 & I5.L5.T7 & 0.007 & 0.006 & 334.44 & 2 & 14.1 \\
\hline 6 & I5.L5.T10 & 0.005 & 0.005 & 234.11 & 2 & 11.8 \\
\hline 7 & II5.L4.T4 & 0.012 & 0.011 & 563.31 & 4.67 & 10.5 \\
\hline 8 & II5.L4.T7 & 0.007 & 0.006 & 337.99 & 4.67 & 8.17 \\
\hline 9 & II5.L4.T10 & 0.005 & 0.005 & 236.59 & 4.67 & 6.8 \\
\hline 10 & II5.L5.T5 & 0.010 & 0.009 & 473.18 & 4.67 & 9.7 \\
\hline 11 & II5.L5.T7 & 0.007 & 0.006 & 337.99 & 4.67 & 8.2 \\
\hline 12 & II5.L5.T10 & 0.005 & 0.005 & 236.59 & 4.67 & 6.8 \\
\hline
\end{tabular}

Table 3. Minimum lateral bar diameter of specimen according to AS3600-2018

\begin{tabular}{cccccccc}
\hline No Column Type & $\mathbf{n}_{\mathbf{b}}$ & $\mathbf{k}_{\text {eff }}$ & $\mathbf{f}_{\text {r.eff }}$ & $\mathbf{f}_{\mathbf{r}}$ & $\mathbf{A}_{\text {bfit }}$ & $\mathbf{D}_{\mathbf{s}}$ \\
\hline 1 & I5.L4.T4 & 8 & 0.62 & 0.5 & 0.804 & 49.17 & 7.91 \\
\hline 2 & I5.L4.T7 & 8 & 0.62 & 0.5 & 0.804 & 29.51 & 6.13 \\
\hline 3 & I5.L4.T10 & 8 & 0.62 & 0.5 & 0.804 & 20.65 & 5.13 \\
\hline 4 & I5.L5.T5 & 8 & 0.62 & 0.5 & 0.804 & 41.31 & 7.25 \\
\hline 5 & I5.L5.T7 & 8 & 0.62 & 0.5 & 0.804 & 29.51 & 6.13 \\
\hline 6 & I5.L5.T10 & 8 & 0.62 & 0.5 & 0.804 & 20.65 & 5.13 \\
\hline 7 & II5.L4.T4 & 12 & 0.69 & 0.5 & 0.72 & 16.64 & 4.60 \\
\hline 8 & II5.L4.T7 & 12 & 0.69 & 0.5 & 0.72 & 9.98 & 3.57 \\
\hline 9 & II5.L4.T10 & 12 & 0.69 & 0.5 & 0.72 & 6.99 & 2.98 \\
\hline 10 & II5.L5.T5 & 12 & 0.69 & 0.5 & 0.72 & 13.98 & 4.21 \\
\hline 11 & II5.L5.T7 & 12 & 0.69 & 0.5 & 0.72 & 9.98 & 3.57 \\
\hline 12 & II5.L5.T10 & 12 & 0.69 & 0.5 & 0.72 & 6.99 & 2.98 \\
\hline
\end{tabular}

\subsection{D Model and Boundary Conditions}

Fig.4 shows the 3D model of the specimen mesh rendered using SALOME 9.2.0. In Fig.4 (a), the cover and core concrete elements are depicted with a different color to differentiate between them. The boundary conditions at both ends were fixed in all directions. The load was given using displacement control at the top of the columns. The reinforcing bars were modeled using $3 \mathrm{D}$ truss elements; the model for Type I is shown in Fig. 4(b) while that for Type II is shown in Fig .4(c).

\section{Results and Discussion}

\subsection{D-NLFEA Stress-Strain Results}

The axial load-deformation curve can be obtained using 3D-NLFEA. The axial stress was further computed by dividing the axial load by the cross-sectional area of the $\mathrm{RC}$ column. The axial strain was obtained by dividing the axial deformation with the total height of the RC column. The final axial stress versus the axial strain of the modeled RC column are shown in Fig. 5, Fig. 6, Fig. 7 and Fig. 8.

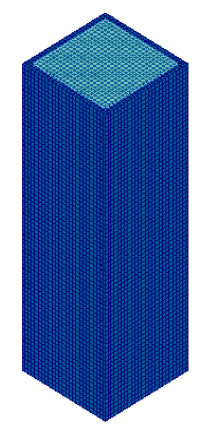

(a)
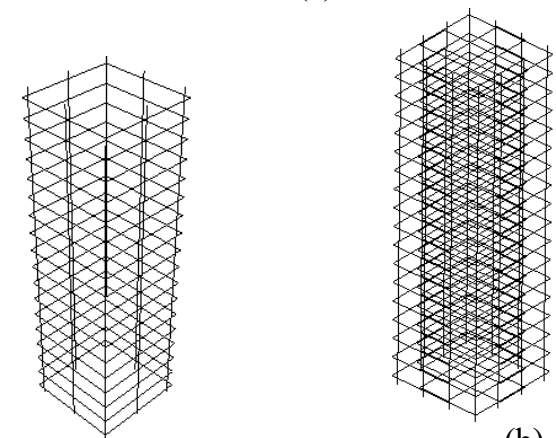

(b)

(c)

Fig. 4 Modeling of Specimens (a) Concrete, (b) Confinement Type I (c) Confinement Type II

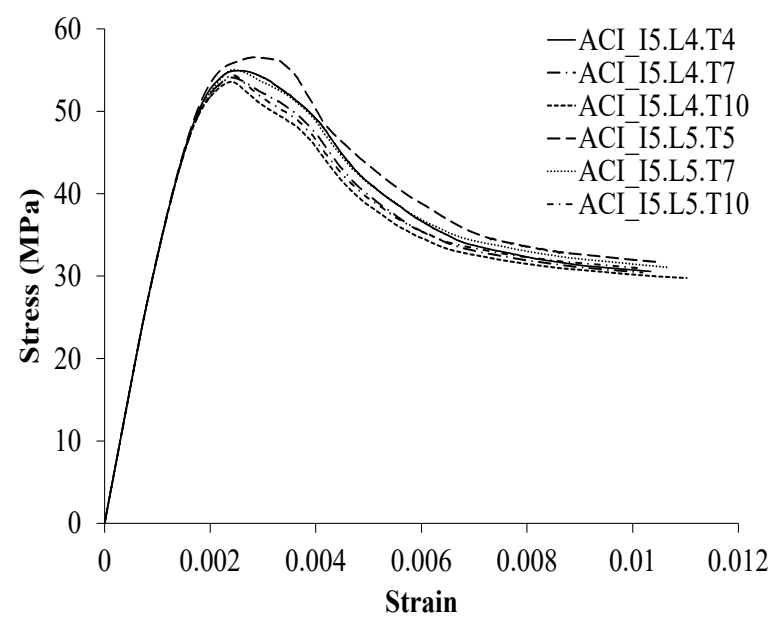

Fig. 5. Specimen stress-strain Diagram Type I according to ACI318-2014

Fig. 5 to 8 show that the peak stress of the RC column was affected by the yield strength of both the longitudinal and confinement reinforcing bar. From Table 4, it can be seen that an increase in the yield strength of the longitudinal bar increases the RC column peak stress while increasing the yield strength of the confining bar reduces the peak stress of RC column. Furthermore, ACI 318-2014 gives higher values of the 
peak stress of the RC Column than AS 3600-2018 does. Table 4. Peak stress of RC column (Type I and II) with constant $A_{\text {sh }} / \mathrm{s}$ (ACI 318-14) and constant confining pressure (AS3600-2018)

\begin{tabular}{cccc}
\hline No & Column Type & $\begin{array}{c}\boldsymbol{f}_{c c} \\
\text { (ACI 318-14) }\end{array}$ & $\begin{array}{c}\boldsymbol{f}_{c c} \\
\text { (AS3600-2018) }\end{array}$ \\
\hline 1 & I5.L4.T4 & 54.93 & 52,53 \\
\hline 2 & I5.L4.T7 & 54.10 & 52.11 \\
\hline 3 & I5.L4.T10 & 53.58 & 52.27 \\
\hline 4 & I5.L5.T5 & 56.57 & 53.12 \\
\hline 5 & I5.L5.T7 & 55.06 & 52.84 \\
\hline 6 & I5.L5.T10 & 54.38 & 51.89 \\
\hline 7 & II5.L4.T4 & 58.00 & 52.03 \\
\hline 8 & II5.L4.T7 & 55.35 & 51.68 \\
\hline 9 & II5.L4.T10 & 53.47 & 51.55 \\
\hline 10 & II5.L5.T5 & 58.12 & 53.12 \\
\hline 11 & II5.L5.T7 & 56.20 & 52.37 \\
\hline 12 & II5.L5.T10 & 54.27 & 52.21 \\
\hline & & & \\
\hline
\end{tabular}

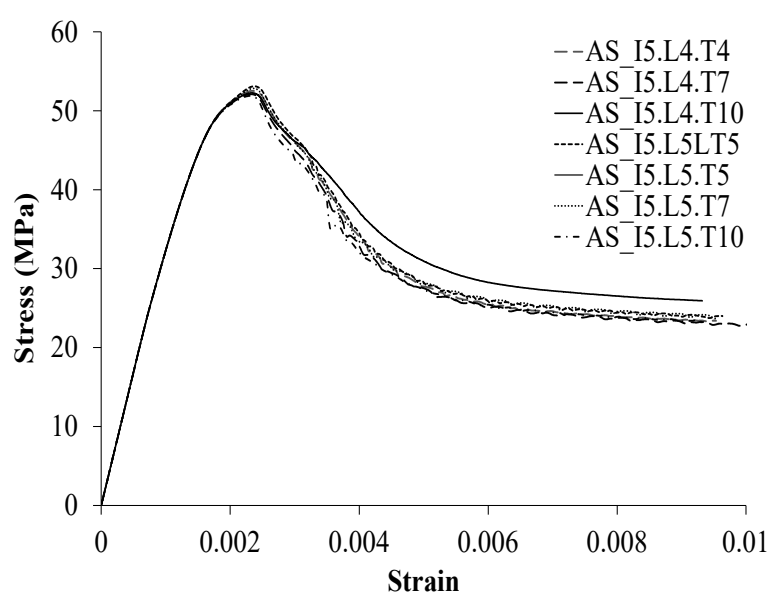

Fig. 6 Specimen stress-strain Diagram Type I according to AS3600-2009

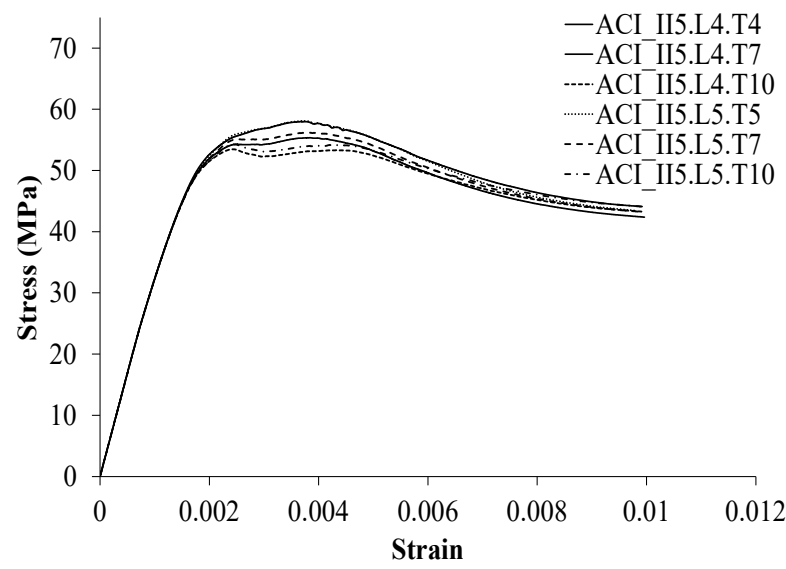

Fig. 7 Specimen stress-strain Diagram Type II according to ACI318-2014

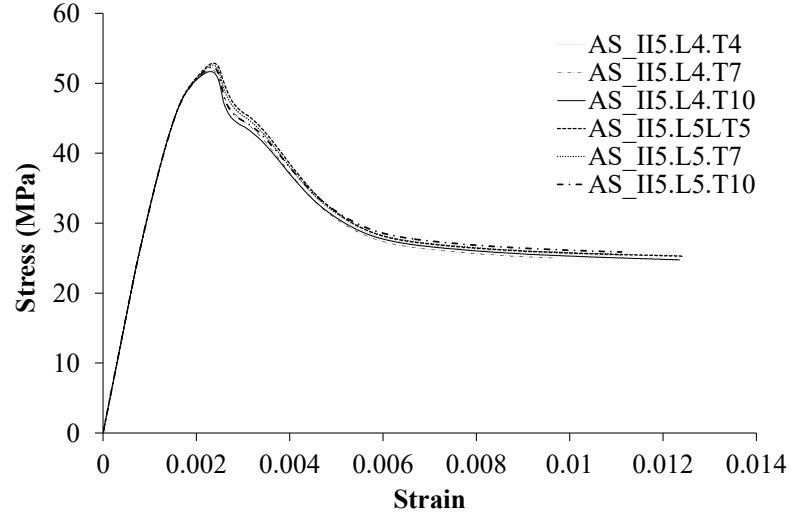

Fig. 8 Specimen stress-strain Diagram Type II according to AS3600-2009

\subsection{Strain Ductility $(\mu)$}

Displacement ductility is related to a structural system or member configuration and its section behavior/ductility [20]. The strain ductility $(\mu)$ is measured as a ratio of the maximum strain recorded after the peak load drops at $85 \%$ of the peak stress to the strain at the first yield [21] which is:

$$
\mu=\frac{\varepsilon_{u}}{\varepsilon_{y}}
$$

The first yield strain is measured by extending the line from the origin crossing to the $75 \%$ of the peak load as shown in Fig.9.

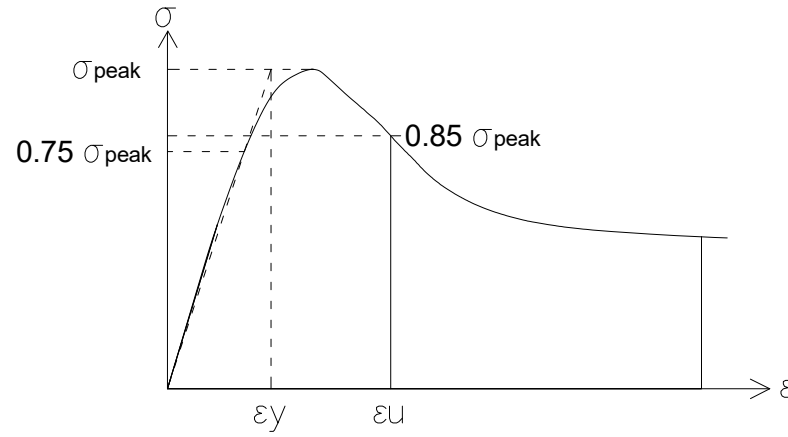

Fig. 9 Strain ductility scheme by Ravzi and Saatcioglu (1994)

Table 5 shows the strain ductility computed for each modeled column (Type I and Type II) based on ACI 31814 and AS 3600-2018; the confining bar ratio $A_{\mathrm{sh}} / \mathrm{s}$ for ACI 318-14 was kept constant while for AS3600-2018, the minimum confining pressure was maintained constant From Table 5, the strain ductility of Type I RC column based on ACI 318-14 is affected by the yield strength of the transverse steel rebar. As the yield strength of the confining bar increases from $420 \mathrm{MPa}$ to $700 \mathrm{MPa}$, the strain ductility increases. However, when the yield strength of the confining bar increases from $700 \mathrm{MPa}$ to $1000 \mathrm{MPa}$, the strain ductility decreases.

For Type II RC columns which comply with the ACI 318-14 confining bar requirement, the strain ductility of the column significantly increases as the yield strength of the transverse steel rebar increases. This shows that the equation used in ACI 318-14 with Type II configuration 
can increase ductility even when the yield strength of the transverse steel rebar is improved to $1000 \mathrm{MPa}$. Therefore, a high-strength rebar for Type II RC columns can be used to replace mild steel rebar without limitations on the yield strength up to $1,000 \mathrm{MPa}$ which is greater than yield strength determined in the codes. The strength limitation specified in the codes is purely intended to deal with construction difficulties in bending high-strength steel to form a tie.

Table 5. Strain ductility of RC column (Type I and II) with constant $A_{\mathrm{sh}} / \mathrm{s}$ (ACI 318-14) and constant confining pressure (AS3600-2018)

\begin{tabular}{cccc}
\hline No & Column Type & $\boldsymbol{\mu}_{\text {ACl318-2014 }}$ & $\boldsymbol{\mu}_{\text {AS3600:2018 }}$ \\
\hline 1 & I5.L4.T4 & 2.388 & 1.864 \\
\hline 2 & I5.L4.T7 & 2.392 & 1.860 \\
\hline 3 & I5.L4.T10 & 2.204 & 1.911 \\
\hline 4 & I5.L5.T5 & 2.270 & 1.837 \\
\hline 5 & I5.L5.T7 & 2.363 & 1.813 \\
\hline 6 & I5.L5.T10 & 2.190 & 1.812 \\
\hline 7 & II5.L4.T4 & 3.497 & 1.858 \\
\hline 8 & II5.L4.T7 & 3.806 & 1.838 \\
\hline 10 & II5.L4.T10 & 4.466 & 1.831 \\
\hline 11 & II5.L5.T5 & 3.420 & 1.840 \\
\hline 12 & II5.L5.T7 & 3.739 & 1.852 \\
\hline
\end{tabular}

Unlike ACI 318-14, the AS 3600-2018 uses the minimum confining pressure. Hence, the computed strain ductility does not alter much as the yield strength of the steel rebar changes. Furthermore, the slight changes in the strain ductility for column designs based on AS 36002018 can be attributed to the different lateral modulus of the internal confining device (confining bar).

\subsection{Ductility Index $\left(I_{10}\right)$}

The $I_{10}$ ductility index measures the ductility of the RC column based on the energy ratio. This energy is computed as the area beneath the axial load $(P)$-nominal strain $(\xi)$ curve. The nominal strain for concentrically loaded RC column is equal to the axial strain. The $I_{10}$ ductility index was proposed by Foster and Attard [22]. Further, Samani et. al [5] also used this $I_{10}$ ductility index to evaluate the ductility of RC columns.

Fig. 10 shows the $I_{10}$ ductility index proposed by Foster and Attard [22]. In Fig. 10, the nominal strain considered when computing the $I_{10}$ ductility index (Point C) is equal to 5.5 times the nominal yield strain (Point A). An elastic-perfectly brittle material has an $I_{10}$ index equal to one, while for an elastic-perfectly plastic model, $I_{10}$ is equal to ten (see Fig. 11) [23]. The $I_{10}$ ductility index can be computed by taking the ratio of the area OEF to the area of $\mathrm{OAB}$ and is:

$$
I_{10}=\frac{\text { Area }_{O C D}}{\text { Area }_{O A B}}
$$

AS 3600-2018 uses the $I_{10}$ ductility index equal to 5.6 as an appropriate baseline for proportioning concrete columns with confinement reinforcement [5]. It should be noted that the structural frame design in AS 3600-2018 is intended only for structural systems with ordinary to intermediate resisting moment frames (OMRF to IMRF). On the other hand, the ACI 318-14 confinement equation is intended for structural systems with special resisting moment frames (SRMF). Hence, it is expected that the $I_{10}$ ductility index of the columns designed using ACI 318-14 confinement requirements should be one magnitude higher than those designed with AS 3600-2018.

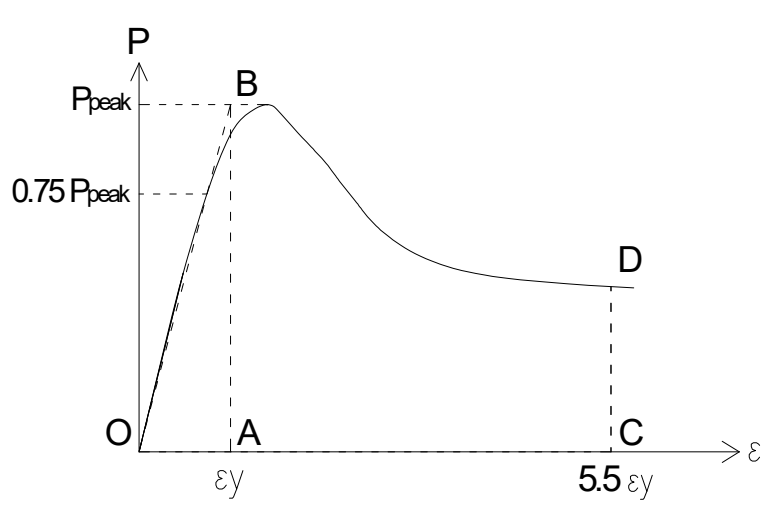

Fig. $10 I_{10}$ ductility index proposed by Foster and Attard [22]

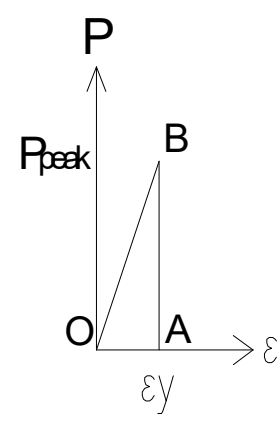

(a)

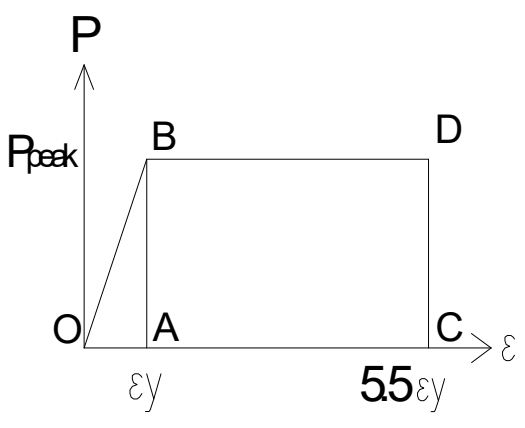

(b)
Fig. $11 I_{10}$ ductility index for (a) elastic-perfectly brittle material and (b) elastic-perfectly plastic material.

Table 6 shows the value of the $I_{10}$ ductility index for all columns. The findings are the same as the strain ductility measurement for Type I RC columns, where the $I_{10}$ decreased as the yield strength of the confining bar increased from $700 \mathrm{Mpa}$ to $1000 \mathrm{Mpa}$. For Type II RC columns, the $I_{10}$ ductility index evaluation is similar to the strain ductility index; that is, using a Type II configuration means $I_{10}$ increases even though the yield strength of the transverse steel rebar is increased to $1000 \mathrm{Mpa}$. Table 6 also shows that the $I_{10}$ value for RC column design with ACI 318-14 was higher by about one magnitude compared to the RC column design with AS 3600-2018. 
Table 6. $I_{10}$ ductility index of RC column (Type I and II) with constant $A_{\text {sh }} / \mathrm{s}$ (ACI 318-14) and constant confining pressure (AS3600-2018)

\begin{tabular}{cccc}
\hline No & $\begin{array}{c}\text { Column } \\
\text { Type }\end{array}$ & I 10_ACI318-2014 & I 10_AS3600:2018 \\
\hline 1 & I5.L4.T4 & 7.520 & 6.390 \\
\hline 2 & I5.L4.T7 & 7.619 & 6.491 \\
\hline 3 & I5.L4.T10 & 7.078 & 6.761 \\
\hline 4 & I5.L5.T5 & 7.534 & 6.354 \\
\hline 5 & I5.L5.T7 & 7.552 & 6.355 \\
\hline 6 & I5.L5.T10 & 7.185 & 6.360 \\
\hline 7 & II5.L4.T4 & 8.690 & 6.352 \\
\hline 8 & II5.L4.T7 & 8.941 & 6.413 \\
\hline 9 & II5.L4.T10 & 9.081 & 6.947 \\
\hline 10 & II5.L5.T5 & 8.671 & 6.361 \\
\hline 11 & II5.L5.T7 & 8.891 & 6.437 \\
\hline 12 & II5.L5.T10 & 9.281 & 6.552 \\
\hline
\end{tabular}

\section{Conclusions}

This paper presented the parametric studies on RC column confined with varying steel yield strength for both the longitudinal and the transverse steel rebar. One of the major findings was that the ACI 318-14 equation for confinement does not give the same level of ductility when steel of different yield strengths was used. On the other hand, the AS 3600-2018 equation for the confining rebar shows an almost similar ductility level for any value of the steel yield strength. This similar ductility level can be obtained by keeping the minimum confining pressure the same. Slight variation in the ductility level was encountered which is believed to be due to the differences in the stiffness of the confining rebar when a high strength confining rebar is used.

Further research can consider more parametric studies with numerous variations in the RC column configurations. Moreover, other combinations of external and/or internal confining devices, as well as different loading conditions, should be investigated to further understand the ductility behavior of RC columns.

\section{References}

1. Thorhallson, E.R. and P.V. Bjarnason, 15 WCEE (2012)

2. Taheri, A., A.S. Moghadam, and A.A. Tasnimi, Int. J. Adv. Struc. Engg. 9(4): p. 325-340 (2017)

3. Sheikh, S.A., S.M. Uzumeri, and M. ASCE J. of Struct. Div. 1079-1102 (1980)

4. Karabinis, A. and P. Kiousis, J. Struc. Engg. 122(3) 267-274 (1996)

5. Samani, A.K., M.M. Attard, and S.J. Foster, Australian J. Struc. Engg. 16(3) 237-250 (2015)

6. Parvez, A., et al., Finite element analysis of HSC column confined with HSS ties.

7. Mander, J.B., M.J. Priestley, and R. Park, J. Struc. Engg. 114(8)1804-1826 (1988)

8. Alavi-Dehkordi, S. and D. Mostofinejad, Mat and Struc. 51(6) 145 (2018)

9. Piscesa, B., Modeling confined concrete using plasticity formulation, in School of Civil and Environmental Engineering. 2018, The University of New South Wales, Sydney, Australia.

10. Piscesa, B., M.M. Attard, and A.K. Samani, Composite Struc. 194 478-493 (2018)

11. Piscesa, B., et al., ACI Struc. J. 114(2) 361 (2017)

12. Piscesa, B., M.M. Attard, and A.K. Samani, Composite Struc. 158 160-174 (2016)

13. Piscesa, B., et al., Engg. Struc. 196109336 (2019)

14. Shanan, M.A., A.H. El-Zanaty, and K.G. Metwally, Int. J. Civil, Env. Struc. Const. and Arch. Engg. 10(7) 955-963 (2016)

15. Saliem, H.M., et al., ACI Struc. J. 530-539 (2009)

16. Venture, N.C.J., <Nerhp-GCR 14-917-30_Use of High-Strength Reinforcement.pdf $>$. US: National Institute of Standards and Technology.

17. Hung, C.-C. and C.-Y. Chueh, Engg. Struc. 122 108120 (2016)

18. Cai, Z.-K., Z. Wang, and T. Yang, Const. Build. Mat. 166 945-955 (2018)

19. Institut, A.C., Building Code Requirements for Structural Concrete (ACI 318-14). American Concrete Institute America.

20. Duan, L. and T.R. Cooper, Concrete Int. 17(11) 6165 (1995)

21. Razvi, S.R. and M. Saatcioglu, ACI Struc. J. 678687 (1994)

22. Foster, S.J. and M.M. Attard, Struc. J. 94(3) 295-303 (1997)

23. McFarlane, A., Struc. Eng. 85(6) 31-37 (2007) 